\title{
Syringomyelia as a Complication of Tuberculous Meningitis
}

\author{
Michael G. Fehlings and Mark Bernstein
}

\begin{abstract}
Tuberculous meningitis may rarely be followed by the development of syringomyelia despite appropriate chemotherapy. In the present paper, we report a case of tuberculous meningitis in a 23-year-old Vietnamese male complicated by a rapidly progressive myelopathy due to granulomatous arachnoiditis which culminated in the development of a syrinx. The relevant literature is reviewed. The present case supports the hypothesis that vasculitic thrombosis of spinal cord vessels leading to ischemic myelomalacia is the mechanism causing postinflammatory syringomyelia.

RÉSUMÉ: La syringomyélie comme complication de la méningite tuberculeuse: compte rendu d'un cas et revue de la littérature. La méningite tuberculeuse peut parfois être suivie de l'apparition d'une syringomyélie malgré une chimiothérapie appropriée. Dans le présent article, nous rapportons un cas de méningite tuberculeuse chez un vietnamien de 23 ans, compliquée par une myélopathie rapidement progressive du à une arachnoïdite granulomateuse qui s'est terminée par le développement d'un syrinx. Nous revoyons la littérature pertinente. Le cas actuel appui l'hypothèse qu'une vasculite thrombotique des vaisseaux de la moelle épinière entraînant une myélomalacie ischémique est le mécanisme causant la syringomyélie postinflammatoire.
\end{abstract}

Can.J. Neurol. Sci. 1992; 19:84-87

Mycobacterium tuberculosis (TB) continues to be an important cause of meningitis in North America, particularly among native Indians and immigrants from third world countries. ${ }^{1,2}$ While the intracranial sequelae of TB have been recently reviewed, ${ }^{3}$ the spinal cord complications of TB meningitis are less well recognized. ${ }^{1,4.5}$ In the present paper, we report a case of TB meningitis complicated by a rapidly progressive myelopathy due to granulomatous arachnoiditis and subsequent syringomyelia.

\section{Case Report}

A 23-year-old Vietnamese male, presented to the Toronto Western Hospital with a six day history of headache, vomiting, neck stiffness and fever. Examination revealed a temperature of $39^{\circ} \mathrm{C}$, nuchal rigidity and no focal neurological signs. A contrast-enhanced computerized tomographic (CT) scan of the head was normal. Analysis of the cerebrospinal fluid (CSF) revealed $11.7 \times 10^{6} /$ litre white blood cells (WBC) (95\% neutrophils), an elevated protein level $(2.3 \mathrm{~g} /)$, hypoglycorrhacia (CSF glucose $1.2 \mathrm{mmol} / \mathrm{l}$; plasma glucose $6.1 \mathrm{mmol} / \mathrm{l}$ ) and a negative gram stain. Enzyme-linked immunosorbant assays (ELISA) of the CSF were negative for cryptococcal and brucella antigens. The patient's fever and neck stiffness did not respond to intravenous antibiotics. Subsequent institution of antituberculous chemotherapy (isoniazid, rifampin, ethambutol, and pyrazinamide) resulted in marked clinical improvement. A second lumbar puncture revealed $4.22 \times 10^{6} / \mathrm{WBC}$ (95\% lymphocytes), an elevated level of protein $(3.2 \mathrm{~g} / \mathrm{l})$ and a normal glucose. All cultures of the CSF and blood were negative. A TB skin test was negative; however, the patient was anergic to candida and tricophyton.

Five weeks after his initial presentation, the patient noted bilateral hand weakness and numbness. Neurological examination revealed normal muscle bulk and tone. Motor power was Grade 3/5 in the hand intrinsics bilaterally and normal proximally in the arms and distally in the legs. Sensory testing revealed a dissociated sensory loss to pain and temperature from C8-T6 bilaterally. Myotatic reflexes were normal and the plantar responses were flexor. A contrast enhanced CT scan revealed several small enhancing lesions in the right temporal lobe, left parietal lobe and pons. A magnetic resonance imaging (MRI) scan of the spine disclosed an enhancing intradural lesion compressing the cord from C6-T7 (Figure 1). Over the ensuing two weeks, the patient showed a deterioration in upper and lower extremity motor function despite intravenous corticosteroids and continued antituberculous chemotherapy. In view of the progressive neurological decline, it was elected to perform a laminectomy to exclude an extradural compressive lesion, and to decompress the spinal cord.

\section{Operation 1}

A C4-T5 laminectomy was performed. The extradural space was normal. The dura was opened widely. The arachnoid was markedly thickened and cloudy in appearance and a biopsy was submitted for pathological examination. The spinal cord appeared swollen and inflamed. Several thrombosed veins were evident on the dorsal surface of the cord and the remaining

From the Division of Neurosurgery, The Toronto Hospital, Western Division and University of Toronto, Toronto Received June 26, 1991. Accepted August 8, 1991

Reprint requests to: Dr. Mark Bernstein, Division of Neurosurgery, The Toronto Hospital, Western Division, 399 Bathurst St., Toronto, Ontario, Canada M5T 2S8 


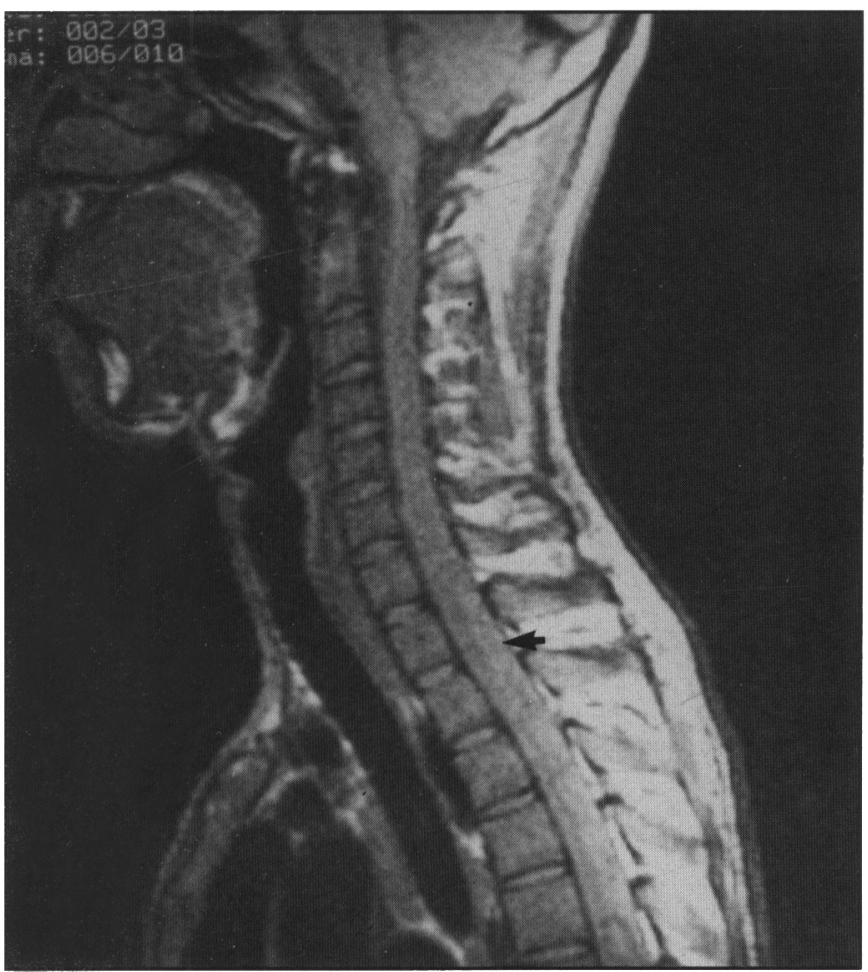

A

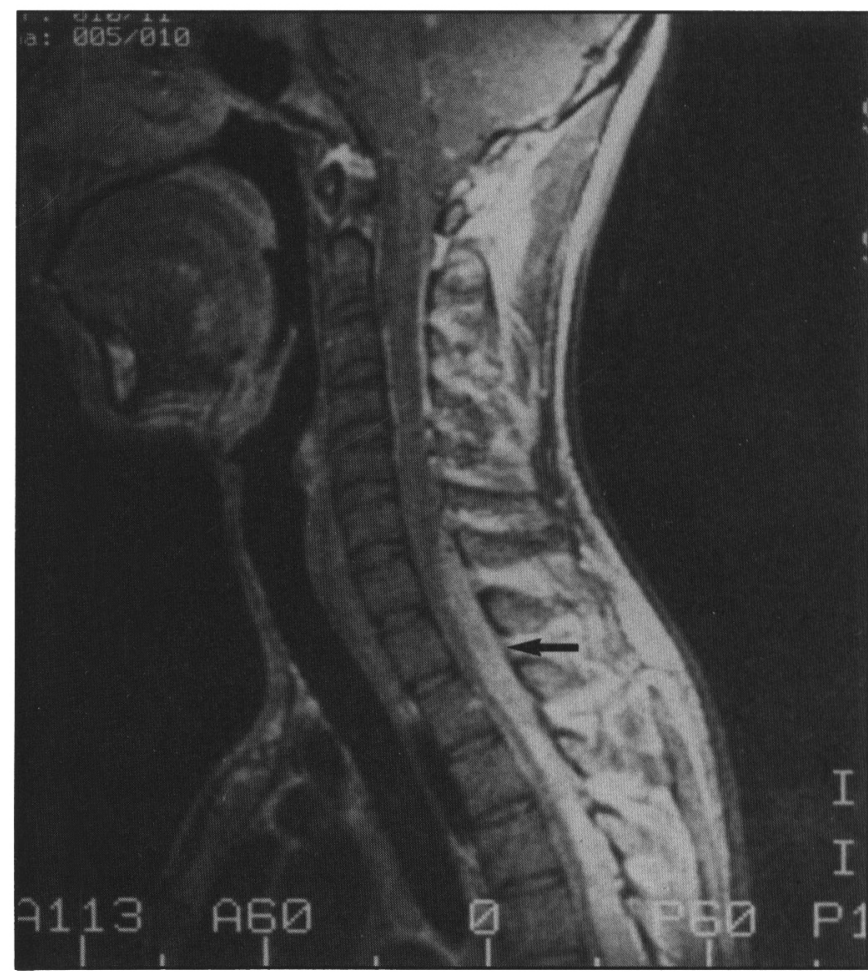

$\mathbf{B}$

Figure 1-A T1-weighted sagittal MRI scan of the cervicothoracic spine (A) showed an intradural extramedullary lesion from C6-T7 (arrow) which enhanced intensely with gadolinium $(\boldsymbol{B})$.

veins appeared distended and dark blue in colour. The dura was left widely open for decompressive purposes.

\section{Pathological Examination}

Histopathological examination of the arachnoid membrane revealed a necrotizing granulomatous inflammation characterized by epithelioid histiocytes (Figure 2). A Ziehl-Nielson stain was positive for acid fast bacilli. Cultures of the biopsy specimens were negative.

\section{Postoperative Course}

The patient was discharged to a rehabilitation facility two weeks postoperatively. He initially made a slow but definite recovery with improved hand and leg function. Three months after the decompressive laminectomy (five months following the initial presentation), the patient noted burning pain along the medial aspect of the right hand, and a deterioration in hand and leg function bilaterally. Neurological examination revealed moderate wasting of the intrinsic muscles of both hands and incomplete paraperesis. Sensory examination revealed hyperpathia along the medial aspect of the right hand and forearm and a dense dissociated sensory loss to pain and temperature from C7-T8 bilaterally.

A gadolinium-enhanced MRI scan (Figure 3) showed intensely enhancing arachnoid in the thoracic region of the spinal cord and a syrinx cavity extending from C7-T10.

\section{Operation 2}

A T6/7 laminectomy was performed. After opening the dura, the cord was noted to be markedly distended. With the aid of intraoperative ultrasound, a Pudenz ventricular catheter was

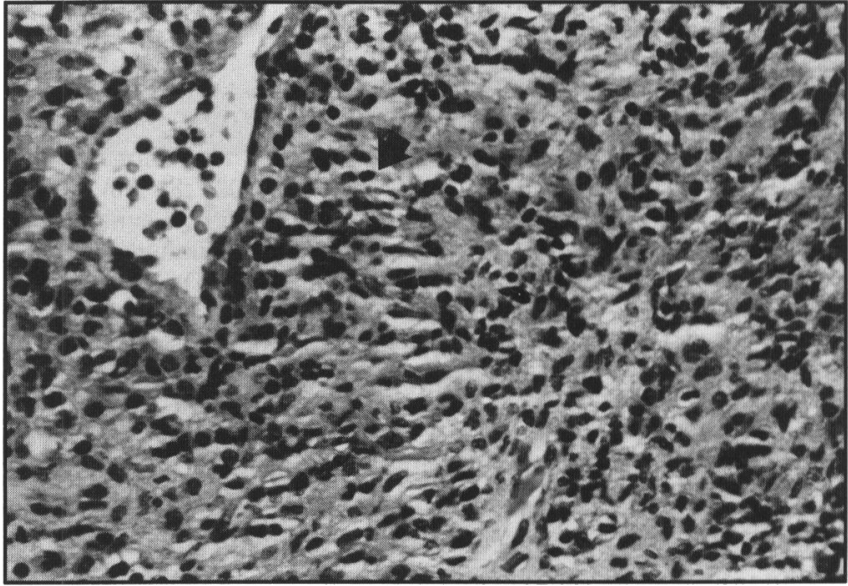

Figure 2 - Histopathological examination of the arachnoid membrane of the thoracic cord disclosed a necrotizing granulomatous inflammation characterized by epithelioid histiocytes (arrow) (hematoxylin-phloxine-saffron; $486 x$; bar $=10 \mu \mathrm{m}$ ).

inserted rostrally into the syrinx cavity via a midline myelotomy. Clear fluid under moderately elevated pressure drained freely from the caudal end of the catheter. A syringoperitoneal shunt was then performed.

\section{Postoperative Course}

Six months following the syringoperitoneal shunt, moderate improvement was noted in the right hand pain but otherwise there was no objective recovery of neurological function. 


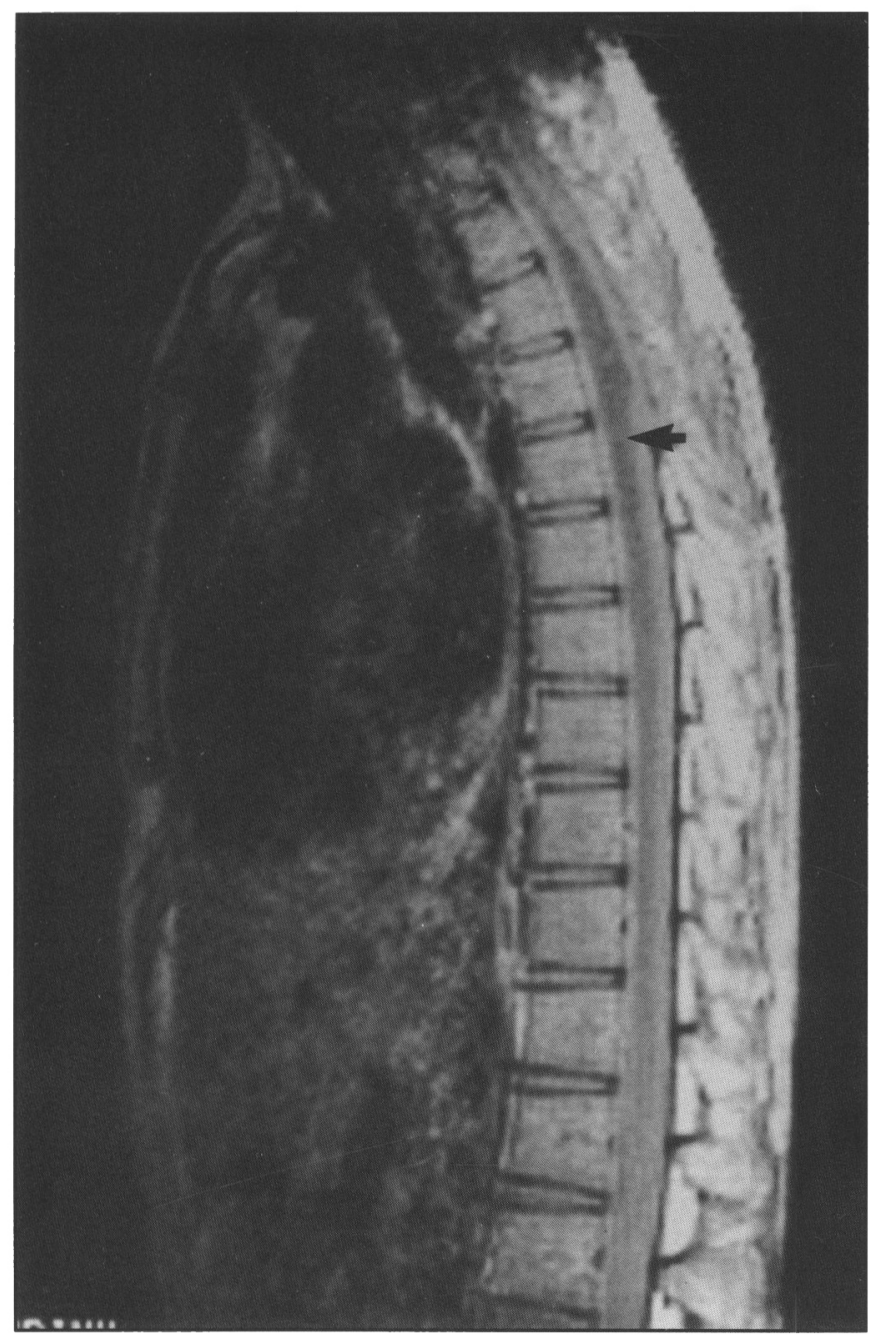

A

\section{Discussion}

Pott's paraplegia due to spinal cord compression secondary to tuberculous vertebral osteomyelitis is a relatively common cause of myelopathy in third world countries where TB is prevalent. ${ }^{6.7}$ Other causes of myelopathy secondary to TB are much less common and include: a) intradural or extradural solitary granulomas of the spinal cord; ${ }^{4,8}$ b) necrotizing granulomatous arachnoiditis with compression and inflammatory thrombosis of spinal cord vessels; ${ }^{1,4}$ and c) syringomyelia secondary to tuberculous arachnoiditis..$^{9-12}$ The present case exemplifies the latter two neurological complications of TB.

As reviewed by Barnett ${ }^{10}$ and Caplan et al.," the association between arachnoiditis and spinal cord cavitation was first made in the nineteenth century by Vulpian (1861) and Charcot and Joffrey (1869). Marinesco ${ }^{13}$ described a patient with chronic "hypertrophic" meningitis and spinal cord cavities who died of pulmonary TB; this likely represents the first case of syringomyelia secondary to tuberculous meningitis. A review of the literature (Table 1) disclosed fifteen other cases of syringomyelia secondary to tuberculous meningitis. ${ }^{9-11,14-18}$ Whereas most previous reports have stressed the long delay

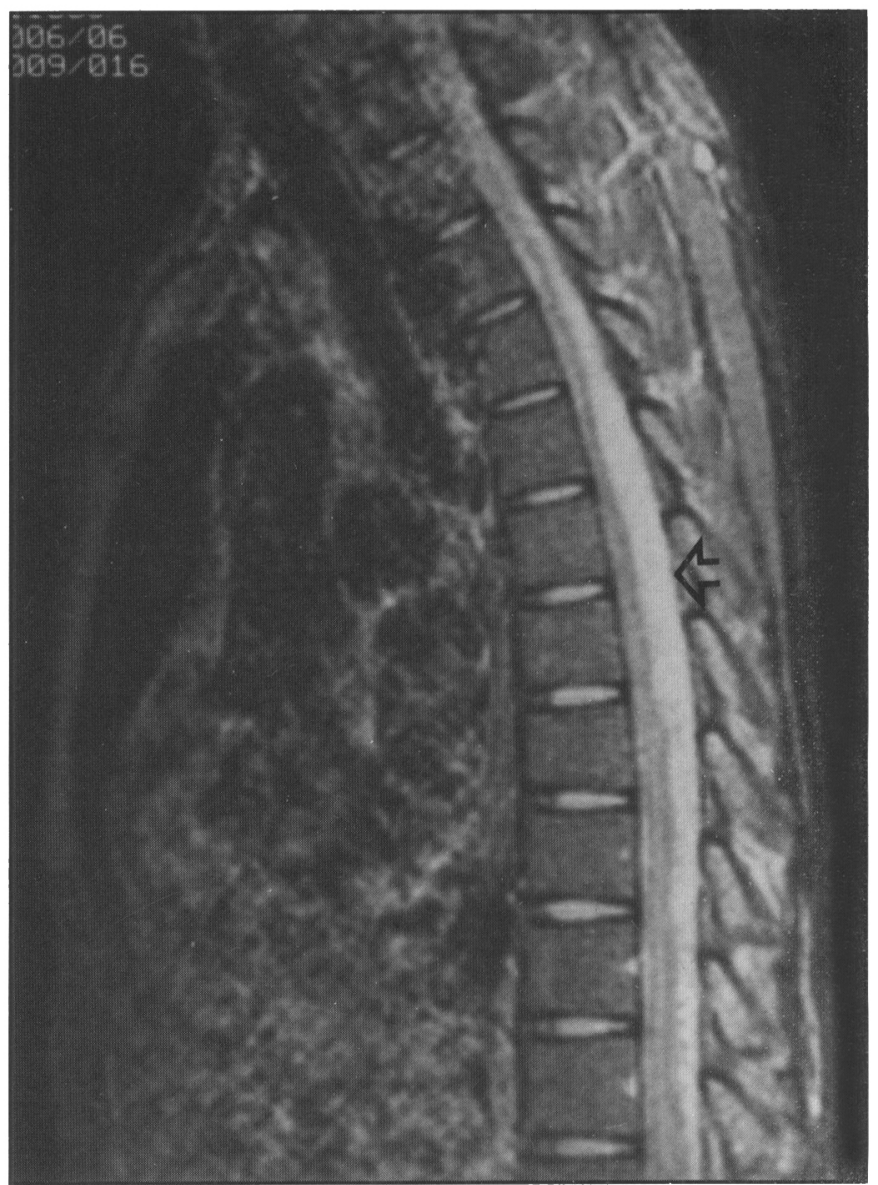

B

Figure $3-($ A) A T1-weighted sagittal MRI scan of the cervicothoracic spine showed a syrinx cavity (arrow) extending from $C 7$ to T10. (B) A gadolinium-enhanced MRI scan revealed the continued presence of an intensely enhancing arachnoid membrane (arrow).

between the onset of TB meningitis and syringomyelia (Table 1 ), the present case is exceptional because of the rapidly progressive myelopathy secondary to a necrotizing granulomatous arachnoiditis which culminated in the development of a syrinx. With the advent of MRI, it is likely that syringomyelia will be increasingly recognized as a potentially surgically treatable cause of tuberculous myelopathy.

As reviewed elsewhere" the mechanisms of syrinx formation following inflammatory arachnoiditis include: a) inflammatory occlusion of spinal cord vessels within the pia-arachnoid leading to ischemic myelomalacia ${ }^{19}$ with subsequent syrinx formation; and b) focal scarring causing a block in the circulation of CSF, thus forcing CSF into the central canal of the cord via VirchowRobin spaces. Moreover, Appleby et al. ${ }^{9}$ reported two cases of basal arachnoiditis at the foramen magnum secondary to TB meningitis (Table 1) which were associated with syringomyelia. Such cases might be responsive to posterior fossa decompression. In contrast, in the present case there was no evidence of basal arachnoiditis. Instead, a necrotizing granulomatous arachnoiditis of the spinal cord (Figure 2) was followed by the rapid evolution of a syrinx. It is likely that the inflammatory arachnoiditis produced an extensive obliterative endarteritis which 
Table 1: Reported Cases of Syringomyelia Following Tuberculous Meningitis ${ }^{1,2}$

\begin{tabular}{|c|c|c|c|}
\hline Reference & Case No. & Age at TBM & $\begin{array}{c}\text { Onset of } \\
\text { Syringomyelia } \\
\text { Following TBM }\end{array}$ \\
\hline \multirow[t]{2}{*}{ Appleby et al. $1969(9)$} & 1 & 19 yrs & $11 \mathrm{yrs}$ \\
\hline & 2 & 13 yrs & $1 \mathrm{yr}$ \\
\hline Barnett $1973(10)$ & 3 & $15 \mathrm{yrs}$ & 22 yrs \\
\hline \multicolumn{4}{|l|}{ Giminez-Roldan et al. } \\
\hline \multirow[t]{4}{*}{$1974(14)$} & 4 & infancy & $20 \mathrm{yrs}$ \\
\hline & 5 & $18 \mathrm{yrs}$ & $4 \mathrm{yrs}$ \\
\hline & 6 & $26 \mathrm{yrs}$ & $6 \mathrm{yrs}$ \\
\hline & 7 & $10 \mathrm{yrs}$ & $8 \mathrm{yrs}$ \\
\hline Savoiardo $1976(15)$ & 8 & 24 yrs & $15 \mathrm{yrs}$ \\
\hline Suzuki et al. 1985 (17) & 9,10 & NA & NA \\
\hline Tsuchiya et al. 1988 (16) & $11-13$ & NA & NA \\
\hline Caplan et al. 1990 (11) & 14 & $40 \mathrm{yrs}$ & $7 \mathrm{yrs}$ \\
\hline \multicolumn{4}{|l|}{ Schon and Bowler } \\
\hline $1990(16)$ & 15 & 40 yrs & $1 \mathrm{yr}$ \\
\hline \multicolumn{4}{|l|}{ Fehlings and Bernstein } \\
\hline 1991 & 16 & $23 \mathrm{yrs}$ & 5 months \\
\hline
\end{tabular}

'TBM: tuberculous meningitis

${ }^{2} \mathrm{NA}$ : information not available

caused ischemic injury to the cord parenchyma. ${ }^{11,19}$ Indeed, MacDonald et al. ${ }^{19}$ have proposed that ischemic myelomalacia antedates the development of syringomyelia due to arachnoiditis. Such a mechanism suggests that although the syrinx cavity may be amenable to surgical decompression, the ischemic injury to cord tissue may be irreversible.

\section{ACKNOWLEDGEMENTS}

The authors thank Dr. Lothar Resch for assistance with the preparation of Figure 2, and Dr. Walter Montanera for assistance with the interpretation of the MRI scans.

\section{REFERENCES}

1. Vlcek B, Burchiel KJ, Gordon T. Tuberculous meningitis presenting as an obstructive myelopathy. J Neurosurg 1984; 60: 196199.

2. Wilkinson HA, Ferris EJ, Muggia AL, et al. Central nervous system tuberculosis: a persistent disease. J Neurosurg 1971; 34: 15-22.

3. Clark WC, Metcalf JC, Muhlbauer MS, et al. Mycobacterium tuberculous meningitis: a report of twelve cases and a literature review. Neurosurgery 1986; 18: 604-610.

4. Brooks W, Fletcher A, Wilson R. Spinal cord complications of tuberculous meningitis. A clinical and pathological study. Q J Med 1954; 23: 275-290.

5. Ransome GA, Monteiro ES. A rare form of tuberculous meningitis. Br Med J 1947; 1: 413-414.

6. Misra RN, Tendon PN, Lahiri AK. Etiological survey of paraplegia. Neurol India 1964; 12: 50-53.

7. Roaf R, Kirkaldy-Willis WH, Cathro AJM. Surgical Treatment of Bone and Joint Tuberculosis. Edinburgh: Livingstone, 1959.

8. Parsons M, Pallis CA. Intradural spinal tuberculomas. Neurology $1965 ; 15: 1018-1022$.

9. Appleby A, Bradley W, Foster J, et al. Syringomyelia due to chronic arachnoiditis at the foramen magnum. J Neurol Sci 1969; 8: 541-464.

10. Barnett H. Syringomyelia associated with spinal arachnoiditis. In: Barnett H, Foster J. Hudgson P. Syringomyelia. London: Saunders, 1973; 220-244.

11. Caplan LR, Norohna AB, Amico LL. Syringomyelia and arachnoiditis. J Neurol Neurosurg Psychiatry 1990; 53: 106-113.

12. Feigen I, Ogata V, Budzelovich G. Syringomyelia: the role of edema in its pathogenesis. J Neuropathol Exp Neurol 1971; 30: 216-232.

13. Marinesco G. Contribution a l'etude de la pachymeningite hypertrophique. Rev Neurol 1916; 30: 233-253.

14. Giminez-Roldan S, Esteban A, Benito C. Communicating syringomyelia following cured tuberculous meningitis. J Neurol Sci 1974; 23: 185-197.

15. Savoiardo M. Syringomyelia associated with postmeningitic spinal arachnoiditis. Neurology 1976; 26: 551-554.

16. Schon F, Bowler J. Syringomyelia and syringobulbia following tuberculous meningitis. J Neurol 1990; 237: 122-123.

17. Suzuki M, Davis C, Symon L, et al. Syringoperitoneal shunt for treatment of cord cavitation. J Neurol Neurosurg Psychiatry 1985; 48: 620-627.

18. Tsuchiya K, Takeshita K, Makita K, et al. Syringomyelia following tuberculous meningitis: report of three cases diagnosed by MR imaging (Japanese). Rinsho-Hoshasen 1988; 33: 1589-1592.

19. MacDonald RL, Findlay JM, Tator CH. Microcystic spinal cord degeneration causing post-traumatic myelopathy. J Neurosurg 1988; 68: 466-471. 